Research Paper

\title{
An intercomparison study of luminescence dating protocols and techniques applied to medieval brick samples from Normandy (France)
}

\author{
Sophie Blain ${ }^{\mathrm{a}, \mathrm{b}, *}$, Ian K. Bailiff ${ }^{\mathrm{a}}$, Pierre Guibert ${ }^{\mathrm{b}}$, Armel Bouvier ${ }^{\mathrm{b}}$, Maylis Baylé ${ }^{\mathrm{c}}$ \\ ${ }^{a}$ Luminescence Dating and Dosimetry Laboratory, University of Durham, South Road, Durham DH1 3LE, UK \\ ${ }^{\mathrm{b}}$ IRAMAT-CRP2A - UMR 5060, CNRS - Université de Bordeaux 3, Pessac, France \\ ${ }^{\mathrm{c}}$ Laboratoire de médiévistique occidentale de Paris, UMR 8589, CNRS - Université de Paris 1, France
}

\section{A R T I C L E I N F O}

Article history:

Received 20 October 2008

Received in revised form

17 February 2009

Accepted 18 February 2009

Available online 27 February 2009

\section{Keywords:}

Medieval

Luminescence

Dating

Intercomparison

Brick

Building

\begin{abstract}
A B S T R A C T
A luminescence dating study has been applied to inform the history and archaeology of two early medieval buildings in north western France. Five bricks were sampled from the medieval churches (10th-11th centuries A.D.) of Rugles and Condé-sur-Risle in Normandy. The samples were divided and tested in the luminescence laboratories of the University of Durham (UK) and of Iramat-CRP2A, University of Bordeaux 3 (France). The fine grain and quartz inclusion techniques were applied, and tests included an examination of the anomalous fading of the luminescence signal from fine grain samples and coarse grains of feldspar. With one exception, the dates produced using the fine grain technique, although corrected for fading, were significantly younger than those produced with quartz inclusions. Although most of the corrected fine grain dates were consistent with the medieval construction of the churches, the brick fabric is of Roman type by archaeological assessment, and this is supported by the quartz coarse grain dates. We conclude that the bricks sampled are re-used, likely to be of Roman origin, and that the reliability of measurements with feldspars in brick fabrics requires wider investigation.
\end{abstract}

(C) 2009 Elsevier B.V. All rights reserved.

\section{Introduction}

Two religious buildings located in the Department of Eure in Normandy, NW France, formed the basis of this study. They were the church of St Martin in Condé-sur-Risle and the church of NotreDame Outre-l'Eau in Rugles. The archaeological purpose of the work was to determine whether the ceramic building materials (CBM) used in the construction of the churches were Roman re-used spolia or of contemporary medieval manufacture. Furthermore, intercomparison studies were performed with the samples divided between the two laboratories, in particular, comparing the dates obtained with the polymineral fine grain and coarse quartz grain techniques, and also evaluating whether the corrections applied for anomalous fading in fine grain data were valid for these materials.

\section{Samples}

Brick cores were obtained using a diamond faced core drill of $38 \mathrm{~mm}$ diameter designed for wet cutting. From the original

\footnotetext{
* Corresponding author.

E-mail addresses: s.e.l.blain@durham.ac.uk (S. Blain), ian.bailiff@durham.ac.uk (I.K. Bailiff), guibert@u-bordeaux3.fr (P. Guibert), bouvier_armel@yahoo.fr

(A. Bouvier), maylis.bayle@wanadoo.fr (M. Baylé).
}

building of the church of St Martin, two bricks (Bdx11984/Dur347-1 and Bdx11985/Dur347-2) from the original 11th century doorway of the nave (Baylé, 2000) were sampled.

Three bricks from the northern walls of the chancel (built upon Roman bath-house remains) and the nave of the church of NotreDame Outre-l'Eau were sampled. One of the sampled bricks (Bdx11979/Dur346-3) from the chancel, had remains of Roman mortar on its lower surface. The second (Bdx11982/Dur346-1) came from the upper part of the northern wall of the nave, within a section of herring-bone pattern. The third brick sampled (Bdx11983/Dur346-2) came from the lower part of this same wall.

Both polymineral fine grain $(3-12 \mu \mathrm{m})$ and coarse quartz grain $(80-200 \mu \mathrm{m})$ techniques were applied in the Bordeaux laboratory to determine the paleodose. The preparation of measurement samples was made following the routine protocols (Blain et al., 2007; Vieillevigne et al., 2006). The coarse quartz grains $(90-150 \mu \mathrm{m})$ technique was selected in the Durham laboratory (Bailiff, 2007).

\section{Determination of paleodose}

\subsection{Protocols}

The paleodose was determined in the Bordeaux laboratory using an additive dose and regeneration procedure with multiple aliquots 
(Guibert et al., 1996). In Durham, the paleodose was determined using a single aliquot OSL regenerative procedure that includes preheat treatment and monitoring of sensitization and thermal transfer (Bailiff, 2007).

\subsection{Fading tests}

The presence of a mixture of quartz, feldspars and other aluminosilicates in fine grain samples requires the extent of anomalous fading of the luminescence to be established (Visocekas et al., 1994; Zink, 1996). Fading tests were performed with K-feldpars only and polymineral grains, containing a mixture of feldspars and aluminosilicates (identified by SEM-EDX analysis), to examine whether they are similar and also whether the stimulation mode (IRSL or TL) affects the fading characteristics.

The stability of the signals following storage under dark conditions and at room temperature was tested by comparing the TL recorded immediately after laboratory irradiation with the TL recorded after a delay of between $2 \mathrm{~h}$ and 2 months following laboratory irradiation. Further tests of fading were also carried out in IRSL, both on coarse grains of feldspars (90-150 $\mu \mathrm{m}$; $\left.\rho<2.58 \mathrm{~g} \mathrm{~cm}^{-3}\right)$ and on polymineral fine grains $(2-10 \mu \mathrm{m})$ at the Durham laboratory. The aim was to compare fading data obtained in both laboratories using similar samples in order to evaluate whether the fading recorded was similar according to the stimulation source and/or the mineralogical fraction used. The samples were bleached ( $100 \mathrm{~s}$ at $280^{\circ} \mathrm{C}$ ), given a $10 \mathrm{~Gy}$ dose and measured after storage periods ranging from $200 \mathrm{~s}$ to $73 \mathrm{~h}$ (Kars et al., 2008). The IRSL was recorded at $75^{\circ} \mathrm{C}$, for $100 \mathrm{~s}$, following a preheat at $220^{\circ} \mathrm{C}$ ( $10 \mathrm{~s}$ hold). The IRSL recorded after these various storage times was then compared.

\subsection{Instrumentation}

In Bordeaux, the TL was recorded with an automated TL-reader built in CRP2A, according to the following conditions: heating to $500{ }^{\circ} \mathrm{C}$ at $4{ }^{\circ} \mathrm{C} / \mathrm{s}$ in wet nitrogen atmosphere $\left(96 \% \mathrm{~N}_{2}, 4 \% \mathrm{H}_{2} \mathrm{O}\right.$ vapour), preheat at $190{ }^{\circ} \mathrm{C}$ for $2 \mathrm{~min}$, spectral window from 350 to $450 \mathrm{~nm}$ (2 Schott BG12 and IR rejection optical filters; phototube EMI 9813 QA). Laboratory irradiations were given by a ${ }^{90} \mathrm{Sr}-{ }^{90} \mathrm{Y}$ beta source delivering ca $0.075 \mathrm{~Gy} / \mathrm{s}( \pm 1.5 \%)$ and a ${ }^{241} \mathrm{Am}$ alpha source delivering $0.21 \mathrm{~Gy} / \mathrm{s}( \pm 5 \%)$ in silica (calibrated by calculation from geometric data of the source, the distance between the source and the sample, the source activity and the energy of the emerging alpha particles).

In Durham, luminescence measurements were performed using a TL-DA-12 semi-automated reader (Risø National Laboratory, Denmark). Optically stimulated luminescence (OSL) was detected after passing through a Hoya U340 filter $(7.5 \mathrm{~mm})$, spectral window 260-390 nm, and OSL decay curves were recorded using blue diode $\left(470 \mathrm{~nm} ; \sim 50 \mathrm{~mW} \mathrm{~cm}^{-2}\right.$ ) stimulation sources. The OSL signal was obtained by integrating the photon counts recorded during the first few seconds of stimulation (typically $5 \mathrm{~s}$ ), which was sufficient to account for at least $80 \%$ of the emission associated with the 'fast'/ 'medium' components. Laboratory irradiations were given by $\mathrm{a}^{90} \mathrm{Sr}_{-}{ }^{90} \mathrm{Y}$ beta source delivering respectively $0.74 \mathrm{~Gy} / \mathrm{min}$. Preheat treatment consisted of holding the aliquot at a temperature selected at $220^{\circ} \mathrm{C}$ for $10 \mathrm{~s}$. The fading experiments were carried out on coarse K-feldspars and polymineral fine grains with a combination of BG39 (spectral window 330-650 nm) and 5.60 (spectral window $330-570 \mathrm{~nm}$ ) detection filters, allowing a detection range centred on the $410 \mathrm{~nm}$ peak.

\section{Annual dose-rate evaluation}

\subsection{Contribution to the dose rate from the sample}

In both laboratories, the components of the annual dose due to radioelements in the bricks were calculated using concentration values of lithogenic radionuclides determined by low-background gamma-spectrometry measurements (Guibert and Schvoerer, 1991 ) with powdered brick samples. Samples were analysed with a high-purity Ge well detector (Canberra-Eurisys Mesures, EGPC 200 P17) in Bordeaux and with a high-purity Ge coaxial detector with a Be window (Canberra, GR2018) in Durham.

Alpha and beta dose rates (Bordeaux) were calculated using the concentration values of lithogenic radionuclides obtained by gamma spectrometry and conversion factors reported by Adamiec and Aitken (1998). An alpha dose-rate contribution must be taken into account since $\mathrm{H}_{2} \mathrm{~F}_{6} \mathrm{Si}$ used to etch the coarse grains (Blain et al., 2007) does not remove the outer alpha irradiated layer of grains. Alpha and beta attenuation factors in coarse grains were calculated using data published by Brennan et al. (1991) and Mejdahl (1979). The alpha sensitivity of the external zone of quartz grains was assumed to be the same as that for the interior of the grains. In Durham, the beta dose rate was evaluated using the gammaspectrometry concentration values as performed by Bordeaux, but used in age calculations the dose rate determined by $\beta$-TLD measurements performed on several aliquots $\left(\sim 2 \mathrm{~cm}^{3}\right)$ of a pulverised portion of brick (Bailiff, 1982). Measurements by ICP-MS (Durham) were also undertaken to determine the average concentration of lithogenic radionuclides in the HF etched quartz used for paleodose determinations.

A value of $5 \pm 3 \%$ was assigned to the average moisture content of bricks, on the basis of relatively dry conditions and good drainage where capillary effects were judged to have been not significant.

\subsection{Gamma and cosmic dose rates}

The gamma and cosmic dose rates were determined by in situ dosimetry using $\mathrm{CaSO}_{4}: \mathrm{Tm}$ (Bordeaux) and $\mathrm{Al}_{2} \mathrm{O}_{3}: \mathrm{C}$ (Durham) dosimetry phosphors. The dosimeter capsules (Bordeaux, plastic tube placed in a $2 \mathrm{~mm}$ thick-wall brass container; Durham, highpurity fused silica tube with $\sim 3 \mathrm{~mm}$ wall thickness) were placed at depths in the walls corresponding to the sampling locations in the walls.

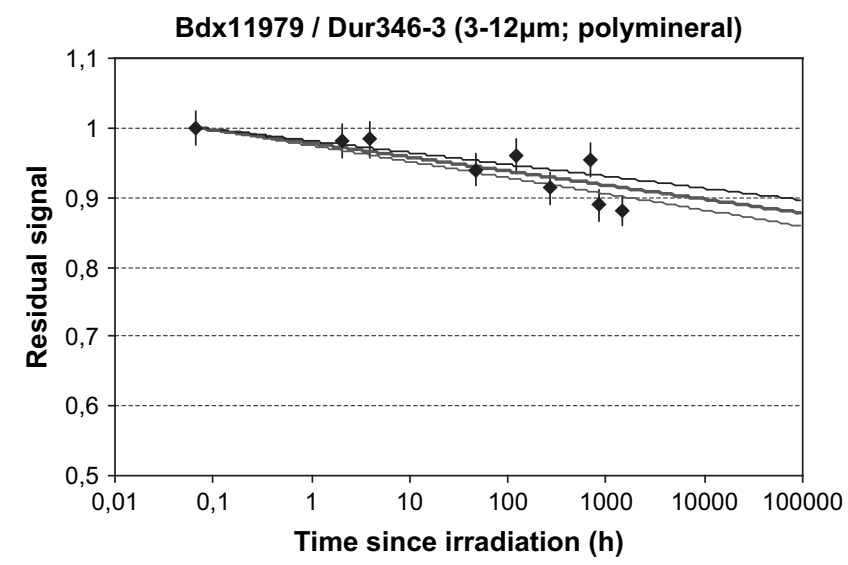

Fig. 1. Fading of TL signal: comparison of the TL recorded after a delay between laboratory irradiation and reading ( $2 \mathrm{~h}-2$ months) and the TL recorded immediately after laboratory irradiation. 
Table 1

Samples Bdx11982/Dur346-1 and Bdx11984/Dur347-1: ratio between the delayed luminescence signal (+72ilh) and the immediate signal.

\begin{tabular}{|c|c|c|c|}
\hline & \multicolumn{3}{|c|}{ Residual $=$ Lum $_{72 \mathrm{~h} \text {-delayed }} / \mathrm{Lum}_{\mathrm{Imm}}$} \\
\hline & Sample Bdx11979/Dur346-2 & Sample Bdx11982/Dur346-1 & Sample Bdx11984/Dur347-1 \\
\hline Polymineral fg (TL) & 0.94 & 0.99 & 0.95 \\
\hline 90-150 $\mu \mathrm{m}$ K-feldspars (IRSL) & - & 0.84 & 0.90 \\
\hline Polymineral fg (IRSL) & - & 0.91 & 0.88 \\
\hline
\end{tabular}

a

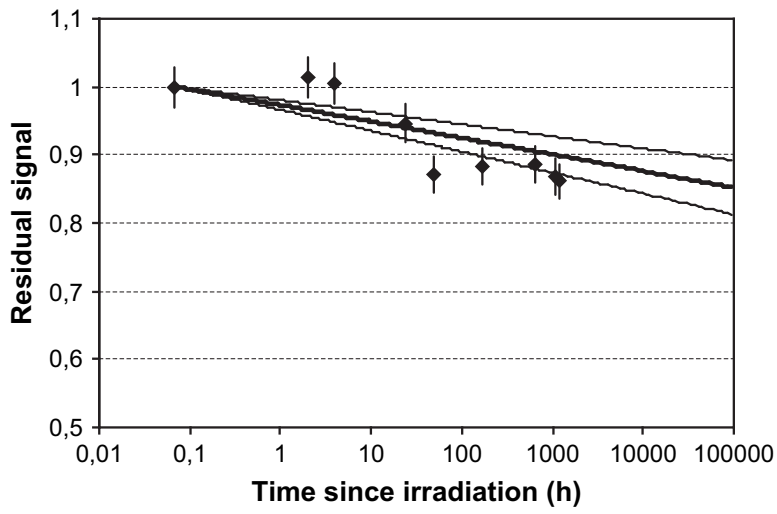

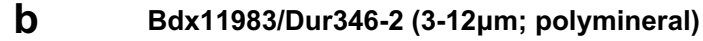

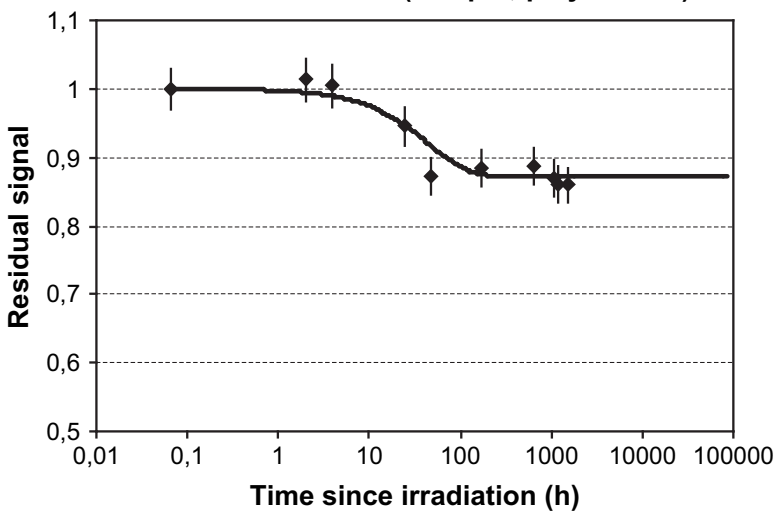

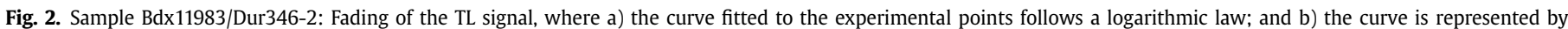
a decreasing exponential function with an asymptote.

\section{Results}

\subsection{Fading tests}

The reduction in TL signal with storage time (Fig. 1) recorded in Bordeaux with the fine grain samples of Bdx11979/Dur346-3 indicates the persistence of fading after 2 months and behaviour (logarithmic) consistent with that predicted by a recombination by tunnelling model (Visocekas et al., 1994; Zink, 1996). The reduction in IRSL and TL recorded in Durham with coarse grains of K-feldspar and polymineral fine grains for samples Bdx11982/Dur346-1 and Bdx11984/Dur347-1 had similar behaviour, and also followed a logarithmic reduction with storage time, as for sample Bdx11979/ Dur346-3. The rate of loss of TL was usually slightly lower than that for IRSL (Table 1). Hence the TL fine grain ages for these three samples were corrected for fading using a logarithmic model only from the TL fading data, back extrapolating to obtain the corrected age (Visocekas, 1985).

In the case of samples Bdx11983/Dur346-2 (Fig. 2a,b) and Bdx11985/Dur347-2, the fading followed a similar form, but two types of fading model can be considered for the pattern of fading observed. The first is the recombination model by tunnelling (Fig. 2a) discussed above; the second is a recombination model

Table 2

Percentage of fading correction on paleodose values.

\begin{tabular}{llc}
\hline & Corrective model $(\mathrm{TL})$ & \% Correction \\
\hline Bdx11982/Dur346-1 & Logarithmic & $26.39 \pm 1.40$ \\
Bdx11983/Dur346-2 & Logarithmic & $25.05 \pm 2.35$ \\
& Exponential & $24.38 \pm 2.25$ \\
Bdx11979/Dur346-3 & Logarithmic & $19.67 \pm 0.46$ \\
Bdx11984/Dur347-1 & Logarithmic & $19.35 \pm 1.5$ \\
Bdx11985/Dur347-2 & Logarithmic & $3.35 \pm 1.00$ \\
& Exponential & $3.35 \pm 0.99$ \\
\hline
\end{tabular}

Table 3

Comparison of paleodose $\left(D_{e}\right)$ values measured in each laboratory. fg refers to the technique of polymineral fine grains and CG to the coarse grains of quartz one.

\begin{tabular}{llll}
\hline Sample & Technique & $\mathrm{D}_{\mathrm{e}} \pm \mathrm{sd}(\mathrm{Gy})$ & \\
\cline { 3 - 4 } & & Bordeaux (TL) & Durham (OSL) \\
\hline Bdx11982/Dur346-1 & CG & $6.15 \pm 0.91$ & $5.27 \pm 0.26$ \\
& $\mathrm{fg}$ (tunnelling) & $5.75 \pm 1.10$ & - \\
Bdx11983/Dur346-2 & $\mathrm{CG}$ & - & $3.96 \pm 0.34$ \\
& $\mathrm{fg}$ (stabilisation) & $6.73 \pm 0.46$ & - \\
& $\mathrm{fg}$ (tunnelling) & $7.34 \pm 0.64$ & - \\
Bdx11979/Dur346-3 & $\mathrm{CG}$ & $6.26 \pm 0.71$ & $5.54 \pm 0.19$ \\
& $\mathrm{fg}$ (tunnelling) & $6.92 \pm 0.58$ & - \\
Bdx11984/Dur347-1 & $\mathrm{CG}$ & $7.77 \pm 0.56$ & $8.70 \pm 0.56$ \\
& $\mathrm{fg}$ (tunnelling) & $8.95 \pm 0.47$ & - \\
Bdx11985/Dur347-2 & CG & - & $4.68 \pm 0.46$ \\
& fg (stabilisation) & $4.07 \pm 0.25$ & - \\
& fg (tunnelling) & $4.05 \pm 0.28$ & - \\
\hline
\end{tabular}

with a stable level similar to a localized transition mechanism (Templer, 1985; Sanderson, 1988) and represented by a decreasing exponential function with a non-zero asymptote (Fig. 2b). Using this model the paleodose is corrected using a coefficient

\section{Table 4}

Concentration of radionuclides measured by ICP-MS from HF etched quartz grains used to determine the paleodose (Samples Bdx11979/Dur346-3 and Bdx11985/ Dur347-2 didn't provide enough material for ICP-MS analyses).

\begin{tabular}{lllll}
\hline Sample & $\mathrm{K}_{\text {int }}(\mathrm{ppm})$ & $\mathrm{U}_{\text {int }}(\mathrm{ppm})$ & $\mathrm{Th}_{\text {int }}(\mathrm{ppm})$ & $\mathrm{I}_{\text {int }}(\mathrm{mGy} / \mathrm{a})$ \\
\hline Bdx11979/Dur346-3 & - & - & - & - \\
Bdx11982/Dur346-1 & $<100$ & 0.06 & 0.48 & 0.034 \\
Bdx11983/Dur346-2 & $<150$ & 0.01 & 0.11 & 0.007 \\
Bdx11984/Dur347-1 & $<200$ & 0.08 & 1.73 & 0.098 \\
Bdx11985/Dur347-2 & - & - & - & - \\
\hline
\end{tabular}


Table 5

Concentration of radionuclides measured by low-background gamma spectrometry with powdered bricks.

\begin{tabular}{|c|c|c|c|c|c|c|}
\hline \multirow[t]{2}{*}{ Sample } & \multicolumn{2}{|l|}{$\mathrm{K}_{\text {ceram }}(\%)$} & \multicolumn{2}{|c|}{$\begin{array}{l}\mathrm{U}_{\text {ceram }}(\text { from Th-234 and U-235) } \\
(\mathrm{ppm})\end{array}$} & \multicolumn{2}{|l|}{$\mathrm{Th}_{\text {ceram }}(\mathrm{ppm})$} \\
\hline & Bordeaux & Durham & Bordeaux & Durham & Bordeaux & Durham \\
\hline Bdx11979/Dur346-3 & $1.16 \pm 0.02$ & $1.15 \pm 0.03$ & $3.67 \pm 0.03$ & $2.93 \pm 0.51$ & $14.90 \pm 0.13$ & $14.70 \pm 1.23$ \\
\hline Bdx11982/Dur346-1 & $1.09 \pm 0.02$ & - & $3.57 \pm 0.03$ & - & $13.36 \pm 0.12$ & - \\
\hline Bdx11983/Dur346-2 & $0.82 \pm 0.01$ & $0.96 \pm 0.02$ & $2.73 \pm 0.07$ & $2.78 \pm 0.30$ & $11.85 \pm 0.12$ & $12.86 \pm 0.69$ \\
\hline Bdx11984/Dur347-1 & $3.19 \pm 0.04$ & $2.67 \pm 0.03$ & $6.74 \pm 0.05$ & $6.78 \pm 0.42$ & $21.52 \pm 0.18$ & $23.10 \pm 0.96$ \\
\hline Bdx11985/Dur347-2 & $1.59 \pm 0.02$ & $1.56 \pm 0.03$ & $1.88 \pm 0.03$ & $2.19 \pm 0.32$ & $11.73 \pm 0.12$ & $13.30 \pm 0.79$ \\
\hline
\end{tabular}

corresponding to the mean of the residual signals recorded for the longer storage measurements, after a three- or two-day delay $(0.87$ for Bdx11983/Dur346-2 and 0.97 for Bdx11985/Dur347-2). Table 2 shows the percentage correction applied to the age for fading. Whatever the fading model chosen (tunnelling or stabilisation) for samples Bdx11983/Dur346-2 and Bdx11985/Dur347-2, the subsequent corrections converged for the two models (Table 3 ).

\subsection{Comparison of paleodose values}

Table 3 shows the paleodose values for each sample, corrected for fading in the case of fine grain samples using the factors given in Table 2. Statistical tests for difference ( $\chi^{2}$ and Student's $t$ test) were applied to the paleodose values for coarse grains measured in Bordeaux and in Durham and found not to be significant $\left(\chi^{2}=1.20\right.$; 1.42; 0.69 respectively).

\subsection{Annual dose}

\subsubsection{Internal grain}

The concentrations of $\mathrm{K}, \mathrm{U}$ and $\mathrm{Th}$, analysed by ICP-MS, in coarse grains of HF etched quartz used in OSL measurements (Durham) were used to calculate the internal grain dose rate (Table 4) - it can be seen that the contribution is relatively small. The internal grain dose rate is used in the age calculation.

\subsubsection{Alpha and beta contribution from the ceramic}

The concentrations of $\mathrm{K}, \mathrm{U}$ and Th measured in powdered ceramic using high resolution gamma ray spectrometry and the calculated beta dose rates obtained using the conversion factors given by Adamiec and Aitken (1998), together with the beta-dose rate values obtained by $\beta$-TLD (Durham) are given in Tables 5 and 6 respectively.
The concentrations of $\mathrm{K}, \mathrm{U}$ and Th (Table 5) determined from the adjacent sections of core allocated to each laboratory are in good overall agreement with average ratios (Bdx/Dur \pm s.d.) of $1.02 \pm 0.14,1.02 \pm 0.17$ and $0.94 \pm 0.06$ respectively, and ranges of $33 \%, 39 \%$ and $14 \%$. The nature of the latter will be investigated in more detail, but given that the two spectrometers had not been previously cross-calibrated, this is an encouraging outcome. The beta-dose rate values calculated using the gamma spectrometer analyses and measured directly using $\beta$-TLD are also in good agreement (average ratio $1.05 \pm 0.08$ (s.d., $n=4$ )).

\subsubsection{Gamma and cosmic-ray dose rate}

The gamma and cosmic dose rates are given in Table 7 (cols. 3 and 4); the uncertainties shown are the experimental precision associated with the dosimeter evaluation. Where measurements were made by each laboratory at the same location, the agreement obtained using different dosimetry phosphors is good (Bdx/Dur, 1.01 average, range $0.97-1.07, n=3$ ). Overall, the measured values of $\mathrm{I}_{\mathrm{env}}$ for the two buildings are broadly similar $(\sim 0.7-1 \mathrm{mGy} / \mathrm{a})$, the largest difference being at Rugles where a disagreement (30\%) is observed for sample Bdx11983/Dur346-2.

The results obtained by each laboratory (Table 7 ) give similar annual dose values, which were predictable for the samples come from adjacent locations (Table 8).

\subsection{Dates}

Fig. 3a shows the results of individual polymineral fine grains (before and after correction of the fading) and coarse quartz grains dates following the conventional dose-rate assessment where it is assumed the brick was manufactured shortly before use in construction and has remained in situ since then (one-phase model). However if bricks used in the structure are of significantly older age (re-used), the dose-rate assessment needs to be

Table 6

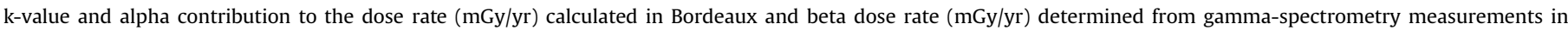

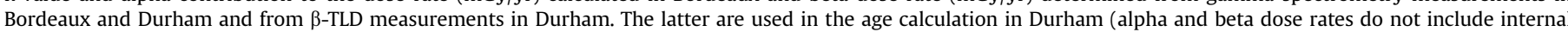
components of quartz).

\begin{tabular}{|c|c|c|c|c|c|c|}
\hline \multirow[t]{2}{*}{ Sample } & \multirow[t]{2}{*}{ Technique } & \multirow{2}{*}{$\frac{\text { k-value }}{\text { Bordeaux }}$} & \multirow[t]{2}{*}{$\mathrm{I}_{\alpha} \pm \sigma_{\text {tot }}(\mathrm{mGy} / \mathrm{yr})$} & \multicolumn{3}{|c|}{$\mathrm{I}_{\beta} \pm \sigma_{\text {tot }}(\mathrm{mGy} / \mathrm{yr})$} \\
\hline & & & & Bordeaux & Durham ( $\gamma$-spec) & Durham ( $\beta$-TLD) \\
\hline Bdx11979/Dur346-3 & $\begin{array}{l}\text { CG } \\
\text { fg }\end{array}$ & $\begin{array}{l}0.03 \pm 0.01 \\
0.09 \pm 0.01\end{array}$ & $\begin{array}{l}0.08 \pm 0.01 \\
1.81 \pm 0.09\end{array}$ & $\begin{array}{l}1.52 \pm 0.05 \\
1.74 \pm 0.05\end{array}$ & $\begin{array}{l}1.58 \pm 0.05 \\
-\end{array}$ & $\begin{array}{l}1.56 \pm 0.04 \\
-\end{array}$ \\
\hline Bdx11982/Dur346-1 & $\begin{array}{l}\text { CG } \\
\text { fg }\end{array}$ & $\begin{array}{l}0.03 \pm 0.01 \\
0.08 \pm 0.01\end{array}$ & $\begin{array}{l}0.08 \pm 0.01 \\
1.60 \pm 0.10\end{array}$ & $\begin{array}{l}1.48 \pm 0.05 \\
1.69 \pm 0.05\end{array}$ & - & $\begin{array}{l}1.68 \pm 0.02 \\
-\end{array}$ \\
\hline Bdx11983/Dur46-2 & $\begin{array}{l}\text { CG } \\
\text { fg }\end{array}$ & 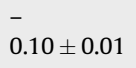 & $\overline{1} .55 \pm 0.06$ & $\overline{-} 1.32 \pm 0.03$ & $\begin{array}{l}1.37 \pm 0.07 \\
-\end{array}$ & $\begin{array}{l}1.18 \pm 0.07 \\
-\end{array}$ \\
\hline Bdx11984/Dur347-1 & $\begin{array}{l}\text { CG } \\
\text { fg }\end{array}$ & $\begin{array}{l}0.03 \pm 0.01 \\
0.12 \pm 0.01\end{array}$ & $\begin{array}{l}0.14 \pm 0.01 \\
4.22 \pm 0.16\end{array}$ & $\begin{array}{l}3.56 \pm 0.12 \\
4.01 \pm 0.11\end{array}$ & $\begin{array}{l}3.38 \pm 0.19 \\
-\end{array}$ & $\begin{array}{l}3.46 \pm 0.21 \\
-\end{array}$ \\
\hline Bdx11985/Dur347-2 & $\begin{array}{l}\text { CG } \\
\text { fg }\end{array}$ & $\begin{array}{l}- \\
0.12 \pm 0.01\end{array}$ & $\overline{1.59} \pm 0.05$ & $\overline{1.79} \pm 0.05$ & $\begin{array}{l}1.74 \pm 0.20 \\
-\end{array}$ & $\begin{array}{l}1.67 \pm 0.17 \\
-\end{array}$ \\
\hline
\end{tabular}


Table 7

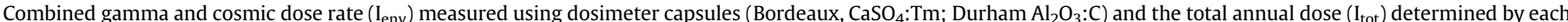

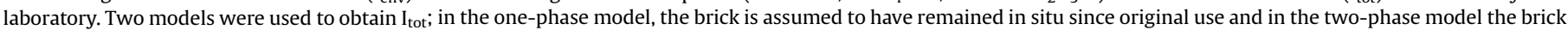

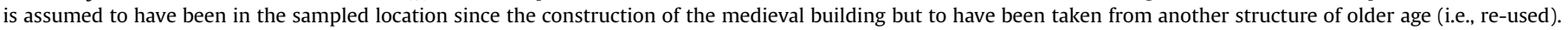

\begin{tabular}{|c|c|c|c|c|c|c|c|}
\hline \multirow[t]{2}{*}{ Sample } & \multirow[t]{2}{*}{ Technique } & \multicolumn{2}{|c|}{$\mathrm{I}_{\text {env }} \pm \sigma_{\text {rand }} \pm \sigma_{\text {tot }}(\mathrm{mGy} / \mathrm{yr})$} & \multicolumn{4}{|l|}{$\mathrm{I}_{\text {tot }} \pm \sigma_{\text {tot }}(\mathrm{mGy} / \mathrm{yr})$} \\
\hline & & Bordeaux & Durham & $\begin{array}{l}\text { Bordeaux } \\
\text { (one-phase model) }\end{array}$ & $\begin{array}{l}\text { Bordeaux } \\
\text { (two-phase model) }\end{array}$ & $\begin{array}{l}\text { Durham } \\
\text { (one-phase model) }\end{array}$ & $\begin{array}{l}\text { Durham } \\
\text { (two-phase model) }\end{array}$ \\
\hline \multirow[t]{2}{*}{ Bdx11979/Dur346-3 } & CG & $0.73 \pm 0.04$ & $0.75 \pm 0.02 / 0.05$ & $2.33 \pm 0.09$ & $2.51 \pm 0.16$ & $2.33 \pm 0.05$ & $2.51 \pm 0.12$ \\
\hline & $\mathrm{fg}$ & $0.74 \pm 0.06$ & - & $4.29 \pm 0.04$ & $4.53 \pm 0.07$ & - & - \\
\hline \multirow[t]{2}{*}{ Bdx11982/Dur346-1 } & CG & $0.74 \pm 0.04$ & $0.75 \pm 0.02 / 0.05$ & $2.29 \pm 0.09$ & $2.61 \pm 0.16$ & $2.46 \pm 0.06$ & $2.76 \pm 0.13$ \\
\hline & $\mathrm{fg}$ & $0.75 \pm 0.06$ & - & $4.03 \pm 0.04$ & $4.36 \pm 0.07$ & - & - \\
\hline \multirow[t]{2}{*}{ Bdx11983/Dur346-2 } & CG & - & $0.96 \pm 0.01 / 0.05$ & - & - & $2.15 \pm 0.06$ & $2.20 \pm 0.12$ \\
\hline & $\mathrm{fg}$ & $0.63 \pm 0.06$ & - & $3.51 \pm 0.04$ & $3.70 \pm 0.07$ & - & - \\
\hline \multirow[t]{2}{*}{ Bdx11984/Dur347-1 } & CG & $0.89 \pm 0.05$ & $0.83 \pm 0.01 / 0.05$ & $4.58 \pm 0.18$ & $5.09 \pm 0.24$ & $4.38 \pm 0.11$ & $4.91 \pm 0.18$ \\
\hline & $\mathrm{fg}$ & $0.90 \pm 0.06$ & - & $9.14 \pm 0.05$ & $9.66 \pm 0.08$ & - & - \\
\hline \multirow[t]{2}{*}{ Bdx11985/Dur347-2 } & CG & - & $0.67 \pm 0.01 / 0.05$ & - & - & $2.35 \pm 0.05$ & $2.54 \pm 0.11$ \\
\hline & $\mathrm{fg}$ & $0.71 \pm 0.06$ & - & $4.09 \pm 0.04$ & $4.29 \pm 0.07$ & - & - \\
\hline
\end{tabular}

adjusted, and it is the gamma and cosmic dose rate where the dose rate may have changed since manufacture of the brick, depending of the history of use. This will affect the coarse grain dates to a greater extent than the fg dates. In previous work a simple twophase dose-rate model was applied to deal with re-used Roman brick in the early medieval Brixworth church (Bailiff, in preparation). Since the coarse grain luminescence dates for the churches of Condé and Rugles calculated using the conventional one-phase dose-rate model indicated an age that is significantly older than the assessed archaeological age for the structure, a two-phase doserate model was applied (Table 7 ).

The dose-rate history for re-used bricks is uncertain in respect of the gamma and cosmic dose rate in the structure where the brick was originally located. The combined gamma and cosmic dose rate for phase 1 was estimated by assuming a typical wall of brick and mortar, with radionuclide composition similar to that for the sampled brick, to a distance of $\sim 0.5 \mathrm{~m}$ surrounding the sampled brick in the original structure. An average dose rate was calculated, weighted by the assumed duration of time in each structure where the archaeologically determined date of the structure was taken as the starting point for the iterative calculation. In this approximation an uncertainty of $\pm 20 \%$ is assigned to the gamma and cosmic dose rate in the assumed phase 1 structure. On average the two-phase (total) coarse grain dose rate is $8 \%$ higher than that for the onephase model (Table 7) for the two buildings.

\section{Discussion}

The Bordeaux and Durham coarse grain date ranges, which are relatively consistent with each other using either one- or two-phase dose-rate models, are significantly older than the polymineral fine grain dates for the Condé samples and for two of the Rugles samples (Bdx11982/Dur346-1 and Bdx11979/Dur346-3). The difference could be due to the use of an inappropriate fading model (Table 8 ), giving rise to an underestimated correction. The slight differences observed in the fading detected may be due to differences in the physical nature of the grains contributing to the luminescence signal (e.g., arising from different etching procedures) and the differences in stimulation, producing different signal components. The notable exception in the fine grain results is one of the Rugles samples (Bdx11983/Dur346-2) which is consistent with the quartz coarse grain date.

Although the archaeological and architectural evidence for the construction supports a medieval date of ca 1000 A.D. that happens to be consistent with the fine grain dates for Condé-sur-Risle samples, the typological dating of the brick suggests Roman manufacture of the brick and hence that the bricks were re-used. At Condé, the limited number of CBM (19) used in the early phases of the building suggests that they were recycled Roman materials. This evidence tends to support the earlier coarse quartz grain dates. At Rugles the CBM may have been taken from one or more

Table 8

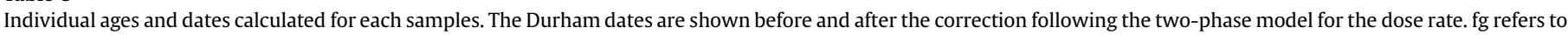
the technique of polymineral fine grains and CG to the coarse grains of quartz one.

\begin{tabular}{|c|c|c|c|c|c|c|c|}
\hline \multirow[t]{2}{*}{ Sample } & \multirow[t]{2}{*}{ Technique } & \multicolumn{2}{|c|}{ Age $\pm \sigma_{\text {tot }}\left(\sigma_{\text {ran }}\right)$ (years) in 2008} & \multicolumn{4}{|l|}{ Dates $\mathrm{AD} \pm 1 \sigma$} \\
\hline & & Bordeaux & Durham & $\begin{array}{l}\text { Bordeaux } \\
\text { (one-phase model) }\end{array}$ & $\begin{array}{l}\text { Bordeaux } \\
\text { (two-phase model) }\end{array}$ & $\begin{array}{l}\text { Durham } \\
\text { (one-phase model) }\end{array}$ & $\begin{array}{l}\text { Durham } \\
\text { (two-phase model) }\end{array}$ \\
\hline Bdx11979/Dur346-3 & $\begin{array}{l}\text { fg }_{\text {(tunnelling) }} \\
\mathrm{CG}\end{array}$ & $\begin{array}{l}1611 \pm 164(129) \\
2683 \pm 321(305)\end{array}$ & $\begin{array}{l}- \\
2387 \pm 144(67)\end{array}$ & $\begin{array}{l}397 \pm 164 \\
-675 \pm 321\end{array}$ & $\begin{array}{l}481 \pm 199 \\
-487 \pm 354\end{array}$ & $\begin{array}{l}- \\
-379 \pm 144\end{array}$ & $\begin{array}{l}- \\
-162 \pm 179\end{array}$ \\
\hline Bdx11982/Dur346-1 & $\begin{array}{l}\text { fg(tunnelling) } \\
\mathrm{CG}\end{array}$ & $\begin{array}{l}1426 \pm 323(258) \\
2684 \pm 408(396)\end{array}$ & $\begin{array}{l}- \\
2144 \pm 129(60)\end{array}$ & $\begin{array}{l}582 \pm 323 \\
-676 \pm 408\end{array}$ & $\begin{array}{l}689 \pm 382 \\
-350 \pm 441\end{array}$ & $-136 \pm 129$ & $-\overline{117 \pm 154}$ \\
\hline Bdx11983/Dur346-2 & $\begin{array}{l}\mathrm{fg}_{\text {(tunnelling) }} \\
\mathrm{fg}_{\text {(stabilisation) }} \\
\mathrm{CG}\end{array}$ & $\begin{array}{l}2094 \pm 205(144) \\
1920 \pm 146(133) \\
-\end{array}$ & $\begin{array}{l}- \\
- \\
1839 \pm 111(60)\end{array}$ & $\begin{array}{l}-86 \pm 205 \\
88 \pm 146 \\
-\end{array}$ & $\begin{array}{l}24 \pm 238 \\
189 \pm 214 \\
-\end{array}$ & $\begin{array}{l}- \\
- \\
169 \pm 111\end{array}$ & $\begin{array}{l}- \\
- \\
208 \pm 142\end{array}$ \\
\hline Bdx11984/Dur347-1 & $\begin{array}{l}\text { CG } \\
\text { fg }_{\text {(tunnelling) }}\end{array}$ & $\begin{array}{l}1695 \pm 138(123) \\
979 \pm 62(40)\end{array}$ & $\begin{array}{l}1985 \pm 130(62) \\
-\end{array}$ & $\begin{array}{l}313 \pm 138 \\
1029 \pm 62\end{array}$ & $\begin{array}{l}482 \pm 212 \\
-\end{array}$ & $\begin{array}{l}23 \pm 130 \\
-\end{array}$ & $\begin{array}{l}244 \pm 136 \\
-\end{array}$ \\
\hline Bdx11985/Dur347-2 & $\begin{array}{l}\mathrm{CG} \\
\mathrm{fg}_{\text {(tunnelling) }} \\
\mathrm{fg}_{\text {(stabilisation) }}\end{array}$ & $\begin{array}{l}- \\
991 \pm 76(59) \\
996 \pm 68(61)\end{array}$ & $\begin{array}{l}1996 \pm 126(63) \\
- \\
-\end{array}$ & $\begin{array}{l}- \\
1017 \pm 76 \\
1012 \pm 68\end{array}$ & $\begin{array}{l}- \\
- \\
-\end{array}$ & $\begin{array}{l}12 \pm 126 \\
- \\
-\end{array}$ & $\begin{array}{l}179 \pm 143 \\
- \\
-\end{array}$ \\
\hline
\end{tabular}



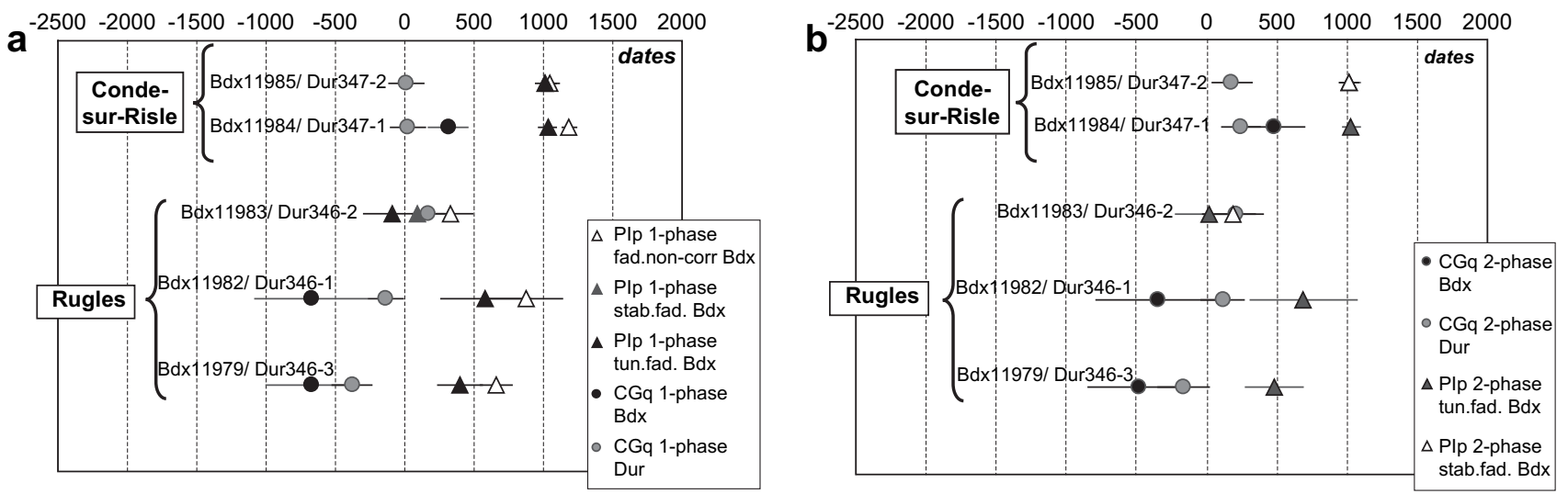

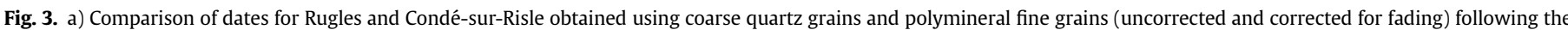
one-phase dose-rate model; b) Comparison of Bordeaux and Durham dates calculated following the two-phase dose-rate model.

buildings of differing age and this would give rise to a range of dates. Nonetheless, two of the coarse grain dates for Rugles have $1 \sigma$ ranges that extend into the latter half of the 1st millennium $\mathrm{BC}$ which is archaeologically inconsistent with the known period of the introduction of brickmaking in Gaul by the Romans. This could be due to the effects of beta dose-rate heterogeneity and is under investigation. However, one of the key questions raised by this work is the reliability with which fine grain samples can be used for dating where the luminescence is emitted mainly by feldspar minerals. Investigation of this issue requires further examination of the Rugles sample for which concordance of fine grain and quartz coarse grain dates was obtained and comparisons performed with material sampled from brick structures with incontrovertible dating control.

\section{Acknowledgements}

This research was supported by the CNRS, Department of Human and Social Sciences within the frame of the GdRE (Groupe de Recherche Européen) "Terres Cuites Architecturales et nouvelles méthodes de datation", the University of Durham (UK), the University of Bordeaux 3 (France), Scott Grainger (Univ.Durham), the Conseil Régional d'Aquitaine, and the European EGIDE project: Programme Alliance.

Editorial handling by: R. Grun

\section{References}

Adamiec, G., Aitken, M.J., 1998. Dose rate conversion factors: update. Ancient TL 16, 37-50.

Bailiff, I.K., 1982. Beta-TLD apparatus for small samples. PACT 6, 72-76.
Bailiff, I.K. Luminescence dating of brick from Brixworth Church - a re-evaluation Report submitted to Brixworth Archaeological Committee for monograph Brixworth Church and Context, in preparation.

Bailiff, I.K., 2007. Methodological developments in the luminescence dating of brick from English late-medieval and post-medieval buildings. Archaeometry 49 827-851.

Baylé, M., 2000. Norman architecture towards the year 1000. In: Proceedings of the Battle Conference (Anglo-Norman Studies) 1999, Woodbridge.

Blain, S., Guibert, P., Bouvier, A., Vieillevigne, E., Bechtel, F., Sapin, C., Baylé, M. 2007. TL-dating applied to building archaeology: the case of the medieval church Notre-Dame-Sous-Terre (Mont-Saint-Michel, France). Radiat. Meas. 42, 1483-1491.

Brennan, B.J., Lyons, R.G., Phillips, S.W., 1991. Attenuation of alpha particle track dose for spherical grains. Radiat. Meas. 18, 249-253.

Guibert, P., Schvoerer, M., 1991. TL dating: low background gamma spectrometry as a tool for the determination of the annual dose. Nucl. Tracks Radiat. Meas. 18 231-238.

Guibert, P., Vartanian, E., Bechtel, F., Schvoerer, M., 1996. Non-linear approach of TL response to dose: polynomial approximation. Ancient TL 14, 7-14.

Kars, R.H., Wallinga, J., Cohen, K.M., 2008. A new approach towards anomalous fading correction for feldspar IRSL dating - tests on samples in field saturation. Radiat. Meas. 43, 786-790.

Mejdahl, V., 1979. Thermoluminescence dating: beta-dose attenuation in quartz grains. Archaeometry 21, 61-72.

Sanderson, D.C.W., 1988. Fading of TL in feldspars: characteristics and corrections Nucl. Tracks Radiat. Meas. 14, 155-161.

Templer, R.H., 1985. The removal of anomalous fading in zircon. Nucl. Tracks 10 , 531-538.

Visocekas, R., 1985. Tunneling radiative recombination in labradorite: its association with anomalous fading of TL. Nucl. Tracks 10, 521-528.

Visocekas, R., Spooner, N.A., Zink, A., Blanc, P., 1994. Tunnel afterglow, fading and infrared emission in thermoluminescence of feldspars. Radiat. Meas. 13, 377-385.

Vieillevigne, E., Guibert, P., Zuccarello, A.R., Bechtel, F., 2006. The potential of optically stimulated luminescence for medieval building; a case study at Termez (Uzbekistan). Radiat. Meas. 41, 991-994.

Zink, A., 1996. Thermoluminescence des feldspaths: emission par effet tunnel et par thermoluminescence dans l'infra-rouge, incidences sur la datation des feldspaths. Doctorat des Universités Paris VII Denis Diderot et Bordeaux III Michel de Montaigne. 